ARTICLE

DOI: $10.1038 / \mathrm{s} 41467-017-02429-9$

\title{
Dendritic core-shell nickel-iron-copper metal/ metal oxide electrode for efficient electrocatalytic water oxidation
}

Peili Zhang ${ }^{1}$, Lin Li ${ }^{2}$, Dennis Nordlund ${ }^{3}$, Hong Chen ${ }^{1}$, Lizhou Fan¹, Biaobiao Zhang ${ }^{1}$, Xia Sheng ${ }^{1}$, Quentin Daniel ${ }^{1}$ \& Licheng Sun (1) ${ }^{1,4}$

Electrochemical water splitting requires efficient water oxidation catalysts to accelerate the sluggish kinetics of water oxidation reaction. Here, we report a promisingly dendritic coreshell nickel-iron-copper metal/metal oxide electrode, prepared via dealloying with an electrodeposited nickel-iron-copper alloy as a precursor, as the catalyst for water oxidation. The as-prepared core-shell nickel-iron-copper electrode is characterized with porous oxide shells and metallic cores. This tri-metal-based core-shell nickel-iron-copper electrode exhibits a remarkable activity toward water oxidation in alkaline medium with an overpotential of only $180 \mathrm{mV}$ at a current density of $10 \mathrm{~mA} \mathrm{~cm}^{-2}$. The core-shell NiFeCu electrode exhibits $\mathrm{pH}$-dependent oxygen evolution reaction activity on the reversible hydrogen electrode scale, suggesting that non-concerted proton-electron transfers participate in catalyzing the oxygen evolution reaction. To the best of our knowledge, the as-fabricated core-shell nickel-ironcopper is one of the most promising oxygen evolution catalysts.

\footnotetext{
${ }^{1}$ Department of Chemistry, KTH Royal Institute of Technology, 10044 Stockholm, Sweden. ${ }^{2}$ PULSE Institute, SLAC National Accelerator Laboratory, Stanford University, Menlo Park, CA 94025, USA. ${ }^{3}$ Stanford Synchrotron Radiation Lightsource, SLAC National Accelerator Laboratory, Menlo Park, CA 94025, USA. ${ }^{4}$ State Key Laboratory of Fine Chemicals, Institute of Artificial Photosynthesis, DUT-KTH Joint Education and Research Centre on Molecular Devices, Dalian University of Technology, 116024 Dalian, China. Correspondence and requests for materials should be addressed to L.S. (email: lichengs@kth.se)
} 
W ater splitting is a sustainable technology to produce hydrogen, which is a carbon-free fuel that offers an attractive route to chemical storage of renewable energy ${ }^{1}$. In practice, water splitting devices need two electrodes: the anode and cathode supported with their respective oxygen evolution reaction (OER) and hydrogen evolution reaction (HER) catalysts. An important property of the catalysts is to reduce the overpotential to drive the half reactions including OER and HER. Among the two half reactions, OER is kinetically sluggish and demands a highly efficient catalyst ${ }^{2}$. Over the past decades, tremendous efforts have been made to synthesize highly efficient, robust, and cost-effective OER catalysts, which has proven difficult. Transition-metal oxides, (oxy)hydroxides, and their derivatives are promising materials thanks to their tunability, abundance, low cost, and potential stability ${ }^{3,4}$. Up to now, most of the efficient transition metal-based catalysts require overpotentials $(\eta)>250 \mathrm{mV}$ to deliver a catalytic current density $(j)$ of $10 \mathrm{~mA} \mathrm{~cm}^{-2} 3$. Recently, transition metal phosphides, sulfides, selenides, and alloys have been reported as non-precious OER catalysts with high activity ${ }^{5-11}$. However, further research shows that these materials are precursors that will undergo superficial $\left(\mathrm{Ni}_{2} \mathrm{P}^{6}, \mathrm{CoP}^{7}, 8 \mathrm{NiFe}^{9}\right.$, and $\mathrm{Ni}_{60} \mathrm{Fe}_{30} \mathrm{Mn}_{10}$ alloy-based electro$\operatorname{des}^{10}$ ) or complete $\left(\mathrm{Ni}, \mathrm{Co}\right.$, and $\mathrm{Fe}$ sulfides ${ }^{11}$ and selenides ${ }^{12}$ ) transformation into metal oxides and/or (oxy)hydroxides during the catalytic process, revealing that the oxide species formed in situ were responsible for the catalytic activity. In comparison with single-centered metal oxides, bi-, and tri-metal-based catalysts show significantly higher catalytic performance toward OER. The improvement can be attributed to the synergy among the different elements ${ }^{13}, 14$. For instance, NiFe-15, NiV-16, $\mathrm{Ni}_{60} \mathrm{Fe}_{30} \mathrm{Mn}_{10^{-}}{ }^{10}$, NiFeCr-based ${ }^{14}$ metal oxides, and gelled FeCoW oxyhydroxide ${ }^{17}$ showed better performance than single metal center $\mathrm{Ni}$ oxides. These reports inspired us to synthesize tri-transition metal-based alloy as templated precursors to highly active core-shell (CS) metal/metal oxide OER catalysts.

Water oxidation requires four electrons. A catalyst containing multiple redox-active metal ions can buffer the multi-electron transfer processes necessary for $\mathrm{OER}^{14}$. Alloying provides a means for mixing a wide range of elements and studying the synergistic effects, but the nature of the physical mixture leads to large crystal size with limited electrochemically accessible surface area and a lack of chemical interaction between different elements ${ }^{18}$. Newly developed fabrication approaches for synthesizing nanostructured alloys by electrodeposition provide a chance to overcome the drawbacks of physical mixture alloys ${ }^{19}$. Hence, nanostructured alloys with multiple redox-active metals may provide new insights into the synergy among different elements and further improve the OER catalytic activity.
Herein, we report a highly active CS metal/metal oxide electrode based on $\mathrm{Ni}, \mathrm{Fe}$, and $\mathrm{Cu}$. The parent alloy with dendritic structure is prepared via electrodeposition. This alloy is used as a precursor to fabricate a CS metal/metal oxide electrode with a high electrochemically active surface area (ECSA). This $\mathrm{CS}-\mathrm{NiFeCu}$ is employed as an electrode for OER, showing an overpotential of only $180 \mathrm{mV}$ for a current density of $10 \mathrm{~mA} \mathrm{~cm}^{-2}$. This is, to the best of our knowledge, the most-efficient OER catalyst in basic media in terms of the overpotential required at $10 \mathrm{~mA} \mathrm{~cm}^{-2}$.

\section{Results}

Synthesis and characterization of the $\mathrm{NiFeCu}$ parent alloy. First, the parent alloy was prepared by electrodeposition, which is one of the most commonly used electrochemical synthesis methods for alloys. This method allows us to control the desired properties, such as the phase composition and the morphology by adjusting the electrochemically deposited conditions ${ }^{20,21}$. Here, we design the alloy by choosing $\mathrm{Ni}, \mathrm{Fe}$, and $\mathrm{Cu}$ as the codepositing elements for the following reasons: (i) single metal center $\mathrm{Ni}, \mathrm{Fe}$, and $\mathrm{Cu}$-based oxides have been reported as efficient catalysts for OER; ${ }^{9,10,22}$ (ii) The co-depositing species stick easily on the same type but hardly stick to particles of the other type $\mathrm{e}^{20}$. (iii) $\mathrm{Cu}$ species is selected to be corroded to enhance the interfacial surface area ${ }^{23-25}$.

The as-designed alloy was prepared by controlled potential electrodeposition on a nickel foam (NF) substrate at $-1.10 \mathrm{~V}$ vs $\mathrm{Ag} / \mathrm{AgCl}$ in citrate aqueous solutions containing $\mathrm{Ni}(\mathrm{Cl})_{2} \cdot 6 \mathrm{H}_{2} \mathrm{O}$ $(80 \mathrm{mM}), \mathrm{Fe}\left(\mathrm{NO}_{3}\right)_{3} \cdot 9 \mathrm{H}_{2} \mathrm{O}(25 \mathrm{mM})$ and $\mathrm{Cu}\left(\mathrm{SO}_{4}\right) \cdot 5 \mathrm{H}_{2} \mathrm{O}(40 \mathrm{mM})$ (more details of electrodeposition mechanism, see Supplementary Fig. 1 and Supplementary Note 1). The electrodeposition leads to a brown film deposited on the surface of nickel foam (Supplementary Fig. 1b). This film was characterized by a combination of various techniques. The X-ray powder diffraction (XRD) spectrum of $\mathrm{NiFeCu}$ alloy reveals that the as-prepared film formed a solid solution with a face-centered cubic (fcc) structure (Supplementary Fig. 2) ${ }^{20}$. The surface of the $\mathrm{NiFeCu}$ alloy was studied by scanning electron microscopy (SEM) and transmission electron microscopy (TEM). SEM images observe that $\mathrm{NiFeCu}$ alloy uniformly deposited onto the nickel foam substrate with a dendritic structure (Fig. 1a) with clearly distinguishable hierarchy and tip-splitting, as shown in Fig. 1a-c. The diameter of branches is distributed in 1.5-3.0 $\mu \mathrm{m}$. Elemental mapping analysis of TEM (Fig. 1d-g) showed that $\mathrm{Fe}$ is homogeneously distributed in the film. Copper prevails at the convex parts, whereas nickel is distributed in the concave ones ${ }^{20}$. Further analysis of the asdeposited ternary system by energy dispersive X-ray spectroscopy

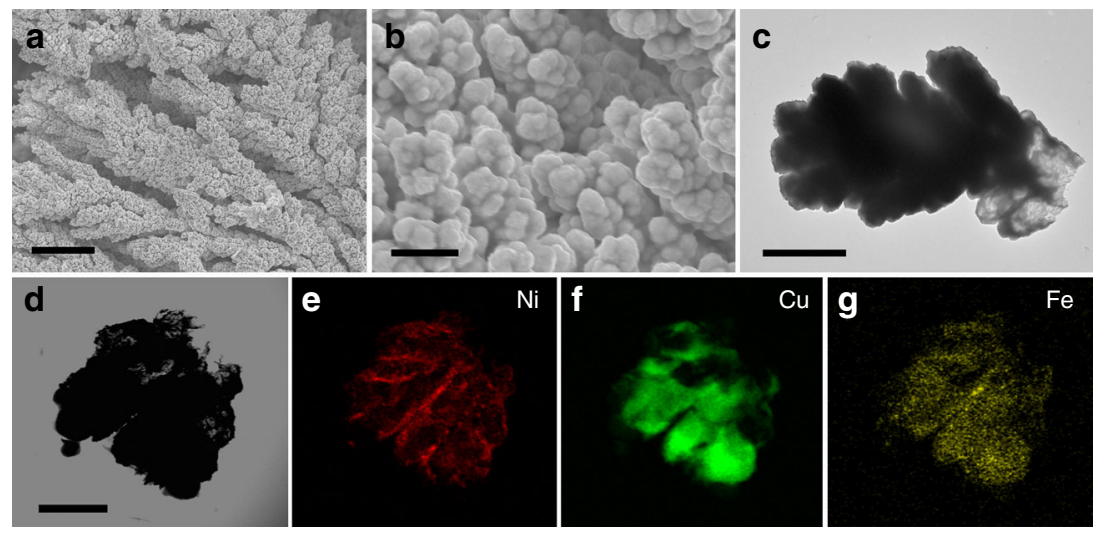

Fig. 1 Microscopy measurements of the NiFeCu parent alloy. a, b SEM images of NiFeCu alloy on nickel foam. Scale bar in $\mathbf{a}$ is $10 \mu \mathrm{m}$, in $\mathbf{b}$ is $2 \mu \mathrm{m}$. $\mathbf{c}$ TEM image of NiFeCu tip. Scale bar in $\mathbf{c}$ is $500 \mathrm{~nm}$. $\mathbf{d}-\mathbf{g}$ TEM images of a branch tip and corresponding elemental mappings. Scale bar in $\mathbf{d}$ is $100 \mathrm{~nm}$ 


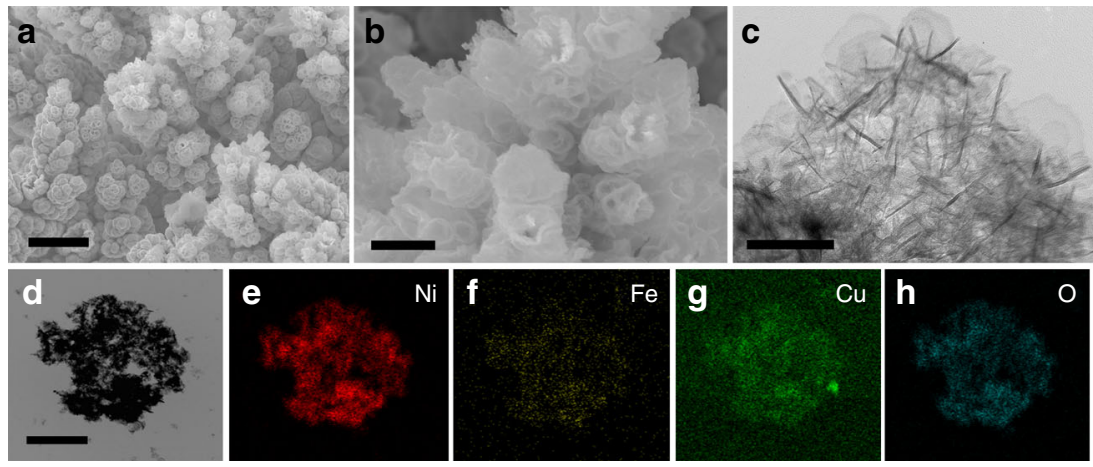

Fig. 2 Microscopy measurements of the CS-NiFeCu electrode. $\mathbf{a}, \mathbf{b}$ SEM images of CS-NiFeCu catalyst on nickel foam. Scale bar in $\mathbf{a}$ is $10 \mu \mathrm{m}$, in $\mathbf{b}$ is $2 \mu \mathrm{m}$. $\mathbf{c}$ TEM image of CS-NiFeCu shell. Scale bar in $\mathbf{c}$ is $50 \mathrm{~nm}$. $\mathbf{d}-\mathbf{h}$ TEM images of CS-NiFeCu shell and corresponding elemental mappings. Scale bar in $\mathbf{d}$ is $100 \mathrm{~nm}$

(EDS) showed that $\mathrm{Ni}, \mathrm{Fe}, \mathrm{Cu}$ are the principal elemental components with an atomic ratio of $\mathrm{Ni}: \mathrm{Fe}: \mathrm{Cu}=10: 1: 21$ (Supplementary Fig. 3).

Synthesis and characterization of the CS-NiFeCu electrode. Next, we produced the metal/metal oxide CS-NiFeCu electrode by dealloying. Dealloying is a commonly used top-down nanosynthesis technique where one or more chemically active elements are selectively oxidized and removed from parent alloy by chemical and/or electrochemical methods ${ }^{10,26-28}$. This keeps the metallic core at high electrical conductivity, which enhances the facile electron transfer during catalytic process. The metal oxide shell is formed on top of the metallic core, which makes the oxide the active catalyst for OER. In details, the CS-NiFeCu electrode was obtained from the $\mathrm{NiFeCu}$ parent alloy by dealloying via potentiostat control using a positive bias voltage at the current density of $200 \mathrm{~mA} \mathrm{~cm} \mathrm{~cm}^{-2}$ in an alkaline solution for $10 \mathrm{~h}$ (Supplementary Fig. 4). Under these dealloying conditions, copper shows the highest chemical activity relative to nickel and iron. Therefore, during the process, loaded $\mathrm{Cu}$ on the surface was gradually dissolved into the solution, whereas a metal oxide layer was generated on the surface, preventing the metallic core from further corrosion (Supplementary Fig. 1c and Supplementary Note 2$)^{29}$. We note that a complete oxidized structure is not desirable owing to the poor electrical conductivity of most metal oxides $^{10,30}$.

The surface of the CS-NiFeCu was studied by SEM and TEM. SEM images show that the CS-NiFeCu electrode had a similar morphology compared with its parent alloy (Fig. 2a). Dendritic structure with moss-like branches was observed by SEM images (Fig. 2a, b). The diameter of branches is distributed in 1.5-3.0 $\mu \mathrm{m}$ range, similar to its parent alloy. Further zoom in SEM images observed that the $\mathrm{Cu}$ prevails in the convex parts of the surface were eroded, leaving a porous shell (Fig. 2b). Magnified TEM image shows that the $\mathrm{CS}-\mathrm{NiFeCu}$ oxides shell cover the branches with a thickness of $250-300 \mathrm{~nm}$ (Fig. 2c and Supplementary Fig. 5).

The XRD patterns (Supplementary Fig. 2) for the CS-NiFeCu catalyst show a series of peaks at $2 \theta=43.4^{\circ}, 50.4^{\circ}, 74.2^{\circ}, 90.0^{\circ}$, and $95.3^{\circ}$, at the same positions as the fcc NiFeCu parent alloy ${ }^{20}$. Two weak diffraction peaks of $\mathrm{CuO}$ at $2 \theta=35.6^{\circ}$ and $38.9^{\circ}$ were observed, corresponding to the residual edged copper ${ }^{31}$. The silence of new diffraction signals in the detection window confirms that the NiFe oxides and/or hydroxides shell surrounding the metallic core in $\mathrm{CS}-\mathrm{NiFeCu}$ electrode are amorphous in nature $^{9,32}$. The XRD analysis of the bulk CS-NiFeCu indicated that only a small amount of the parent alloy was transformed into oxide during dealloying.
To better understand the elemental composition and degree of oxidation, EDS analysis was applied to the bulk material and the oxide shell of CS-NiFeCu. EDS analysis of the bulk CS-NiFeCu catalyst shown an elemental composition (atomic) of $\mathrm{Ni}, \mathrm{Fe}, \mathrm{Cu}$, $\mathrm{O}$ at $\mathrm{Ni}: \mathrm{Fe}: \mathrm{Cu}: \mathrm{O}=10: 1: 16: 3$ (Supplementary Fig. 6) compared with $\mathrm{Ni}: \mathrm{Fe}: \mathrm{Cu}=10: 1: 21$ for the parent alloy $\mathrm{NiFeCu}$. The metal to oxygen ratio in the $\mathrm{CS}-\mathrm{NiFeCu}$ catalyst is $37: 3$, which is far from full oxidation. The reduced amount of $\mathrm{Cu}$ present in $\mathrm{CS}-\mathrm{NiFeCu}$ suggests the loss of $\mathrm{Cu}$ during the dealloying process. During TEM analysis, oxide shell debris was selected for further EDS analysis (Supplementary Fig. 7), showing an atomic proportion of $\mathrm{Ni}: \mathrm{Fe}: \mathrm{Cu}: \mathrm{O}=10: 1: 10: 26$, which is consistent with an oxide surface of $\mathrm{CS}-\mathrm{NiFeCu}$.

Elemental mapping analysis of the oxide shell (Fig. 2d-h) show that $\mathrm{Ni}, \mathrm{Cu}, \mathrm{Fe}$, and $\mathrm{O}$ are homogeneously distributed in the oxide shell, and the initial $\mathrm{Cu}$-rich parent alloy taps have lost about half of its $\mathrm{Cu}$ during the dealloying process. High-resolution TEM image of $\mathrm{CS}-\mathrm{NiFeCu}$ oxide shell show lattice fringes typical of an amorphous (disorder) material, which is different from that of the crystalline parent alloy (Fig. 3a, b). The selected area electron diffraction (SAED) pattern of the shell is typically a halo feature, further indicated that the oxide shell is in the amorphous state (Supplementary Fig. 8). The SEM, TEM, EDS, and XRD analysis of the bulk CS-NiFeCu clearly indicated that only the surface of the parent alloy was transformed into oxide shell. Furthermore, a loading amount of $10.2 \pm 0.5 \mathrm{mg} \mathrm{cm}^{-2}$ was detected by weight (High precision electronic balances, Mettler Toledo). Among them, $\sim 1.6 \mathrm{mg} \mathrm{cm}^{-2}$ of that was contributed to OER, roughly calculated by the accumulated charge for $\mathrm{Ni}^{2+} / \mathrm{Ni}^{3+}$ transformation (more details, see Supplementary Fig. 9 and Supplementary Note 3$)^{9}$.

The electronic states of the $\mathrm{CS}-\mathrm{NiFeCu}$ electrode surface were further analyzed by X-ray photoelectron spectroscopy (XPS). In the XPS spectra, Ni shows a distinct $2 \mathrm{p}_{3 / 2}$ peak around $855.7 \mathrm{eV}$ (Fig. 3c) along with a strong satellite indicative of divalent $\mathrm{Ni}$. Iron shows a fairly broad Fe $2 \mathrm{p}_{3 / 2}$ peak around $710.8 \mathrm{eV}$ along with a small but significant satellite near $720 \mathrm{eV}$ that is associated with $\mathrm{Fe}^{3+}$ (Fig. 3d). The main $\mathrm{Cu} 2 \mathrm{p}_{3 / 2}$ peak $(934.1 \mathrm{eV})$ is accompanied with a strong satellite that can be uniquely ascribed to divalent $\mathrm{Cu}$ (Fig. 3e). The XPS spectra are thus consistent with an oxidized surface consisting primarily of $\mathrm{Ni}^{2+}, \mathrm{Fe}^{3+}$, and $\mathrm{Cu}^{2+}$ oxide $^{15,31}$. The main peak in the $\mathrm{O} 1 \mathrm{~s}$ spectrum was at $530.6 \mathrm{eV}$ (Fig. 3f), attributed to metal oxide ${ }^{15,31}$.

To better understand the valence state of $\mathrm{Ni}, \mathrm{Fe}$, and $\mathrm{Cu}$ in these samples, we have measured X-ray absorption spectroscopy (XAS) on the $\mathrm{Ni}, \mathrm{Fe}$, and $\mathrm{Cu} L_{2,3}$-edges. Metal $L$-edge XAS is a powerful probe of the local electronic structure that displays sensitive to the valency, spin, and symmetry of the metal atom. Figure $3 \mathrm{~g}$ shows the normalized soft-XAS Ni $L_{2,3}$-edge spectra of 

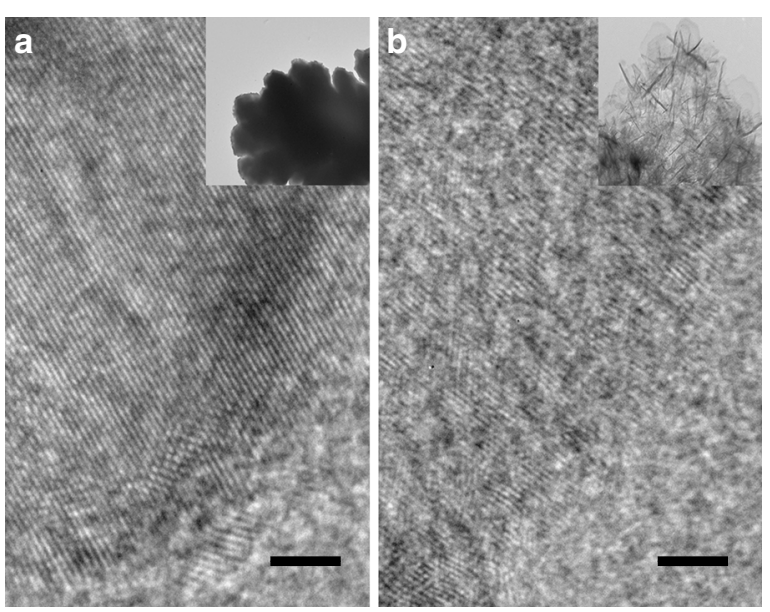

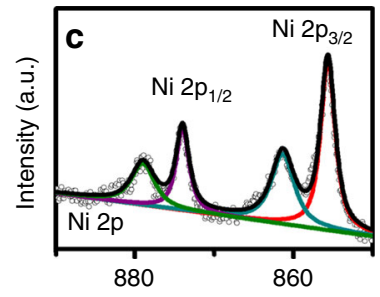

Binding energy (eV)

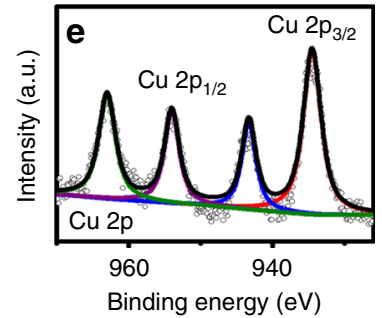

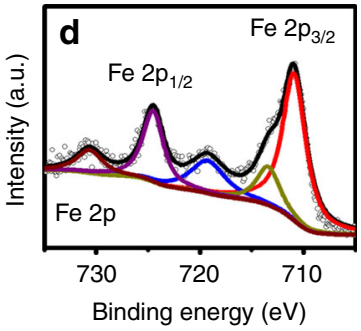

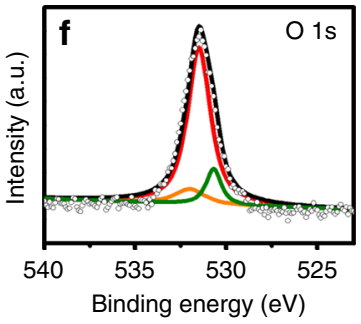

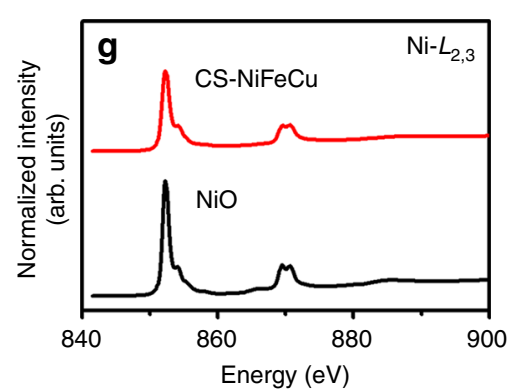
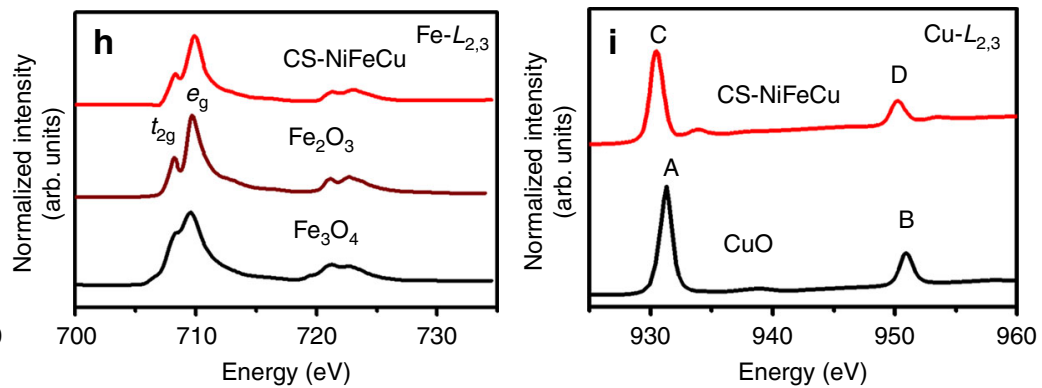

Fig. 3 HRTEM, XPS, and XAS measurements. High-resolution TEM images of NiFeCu alloy (a) and CS-NiFeCu (b), and the insets are the low magnification view for the overall materials. Scale bars in $\mathbf{a}$ and $\mathbf{b}$ are $2 \mathrm{~nm}$. XPS spectra of Ni 2p (c), Fe 2p (d), Cu 2p (e) and O 1s (f) on the surface of CS-NiFeCu electrode. Normalized soft-XAS Ni $L_{2,3}$-edge spectra (g), Fe $L_{2,3}$-edge spectra $(\mathbf{h})$ and $\mathrm{Cu} L_{2,3}$-edge spectra (i) of CS-NiFeCu electrode together with $\mathrm{NiO}$, $\mathrm{Fe}_{3} \mathrm{O}_{4}, \mathrm{Fe}_{2} \mathrm{O}_{3}$, and $\mathrm{CuO}$ as references

$\mathrm{CS}-\mathrm{NiFeCu}$ in comparison with $\mathrm{NiO}$ as a reference. The CS$\mathrm{NiFeCu}$ is nearly identical to $\mathrm{NiO}$ apart from a slight broadening, which suggests that the oxidized $\mathrm{Ni}$ at the surface is primarily divalent $\mathrm{Ni}^{2+33}$. Figure $3 \mathrm{~h}$ shows the $\mathrm{Fe} L_{2,3}$ spectra of CS$\mathrm{NiFeCu}$ together with powder references from $\mathrm{Fe}_{2} \mathrm{O}_{3}\left(\mathrm{Fe}^{3+}\right)$ and $\mathrm{Fe}_{3} \mathrm{O}_{4}$ (two types of $\mathrm{Fe}^{3+}$ and one $3 \mathrm{rd} \mathrm{Fe}^{2+}$ ). The CS-NiFeCu is very similar to $\mathrm{Fe}_{2} \mathrm{O}_{3}$, showing the characteristic absorption profile of high spin $\mathrm{Fe}^{3+}$ in octahedral coordination ${ }^{34}$. Figure $3 \mathrm{i}$ shows normalized soft-XAS $\mathrm{Cu} L_{2,3}$-edge spectra of CS-NiFeCu in comparison with $\mathrm{CuO}$ as a reference. The energy separation between $L_{3}\left(\mathrm{Cu} 2 \mathrm{p}_{3 / 2}\right)$ and $L_{2}\left(2 \mathrm{p}_{1 / 2}\right)$ is determined by the spinorbit coupling, and it is dependent on the oxidation states of $\mathrm{Cu}$, which is $19.0 \mathrm{eV}$ for $\mathrm{CuO}$ and $21.0 \mathrm{eV}$ for $\mathrm{Cu}_{2} \mathrm{O}^{35}$. Our measurements show the $L_{3}-L_{2}$ splitting is $19.7 \mathrm{eV}$ for $\mathrm{CuO}$, which is similar to the $L_{3}-L_{2}$ splitting in CS-NiFeCu. We note that there is $0.7 \mathrm{eV}$ shift to lower energy compared with peaks in $\mathrm{CuO}$. This shift could be related to the different configuration of $\mathrm{Cu}$ atoms and more electron density in $\mathrm{Cu}$ atoms in $\mathrm{CS}-\mathrm{NiFeCu}$ compared with $\mathrm{CuO}^{36}$. The small peak shifted by $2.1 \mathrm{eV}$ from the main peak is attributed to a metallic copper peak ${ }^{36}$. These data were collected in total electron yield (TEY). In addition to it, we also measured fluorescence yield (FY) simultaneously shown in supporting information (Supplementary Fig. 10). The FY probe deeper than TEY measurements. In fact, they show the expected results that more of the metallic core can be observed in FY measurements when the measurements probe deeper.

It is well established that the X-ray absorption spectra at $\mathrm{O} K$ edge probe give rise to a significant pre-edge intensity in transition-metal complexes owing to the hybridization of the O 2p states with the TM $3 \mathrm{~d}$ state that become accessible through the $\mathrm{O} K$-edge dipole transitions $(1 \mathrm{~s}->2 \mathrm{p})^{37}$. Supplementary Fig. 11 shows the normalized XAS O K-edge spectra of CS$\mathrm{NiFeCu}$ in comparison with $\mathrm{CuO}, \mathrm{FeO}, \mathrm{Fe}_{2} \mathrm{O}_{3}$, and $\mathrm{NiO}$ references. $\mathrm{CS}-\mathrm{NiFeCu}$ shows numerous peaks buried in a broad feature representative of the mixture of hybridized O 2p-TM $3 \mathrm{~d}$ states. It is outside of the scope of this article to disentangle these contributions.

Oxygen-evolution catalysis. The electrocatalytic performances of $\mathrm{CS}-\mathrm{NiFeCu}, \mathrm{NiFe}, \mathrm{NiCu}$, and $\mathrm{Ni}$ foam toward OER in $1 \mathrm{M} \mathrm{KOH}$ aqueous solution were measured as shown in Fig. 4. NiFe and $\mathrm{NiCu}$ electrodes were prepared under the same conditions as CS$\mathrm{NiFeCu}$, but without the participation of the third metal $\mathrm{Cu}$ or Fe, respectively (Supplementary Fig. 12). The state-of-the-art $\mathrm{NiFe}$ LDH (layered double hydroxide) catalyst was prepared as a previously reported method for direct comparison ${ }^{38,} 39$. All the data were recorded in a standard three-electrode electrochemical cell using an $\mathrm{Ag} / \mathrm{AgCl}(3 \mathrm{M} \mathrm{KCl})$ as a reference electrode and a $\mathrm{Pt}$ plate $\left(4 \mathrm{~cm}^{2}\right)$ as the counter electrode. The polarization curve of $\mathrm{CS}-\mathrm{NiFeCu}$ shows the best catalytic activity among the five electrodes, delivering much higher current density at the same overpotential than the others (Fig. 4a). For further clear comparison of the analysis data, the overpotentials at a catalytic current density of $10 \mathrm{~mA} \mathrm{~cm}^{-2}$ were plotted and shown in Fig. $4 \mathrm{~b}$. The CS-NiFeCu electrode required an overpotential of $180 \mathrm{mV}$, which was $66,79,81$, and $182 \mathrm{mV}$ lower than that of $\mathrm{NiFe} \mathrm{LDH}$, $\mathrm{NiFe}, \mathrm{NiCu}$, and nickel foam, respectively (Fig. $4 \mathrm{~b}$ ). Another way to view the data is to fix the overpotential at $\eta=250 \mathrm{mV}$, as shown in Fig. 4c. The CS-NiFeCu electrode delivered a current 

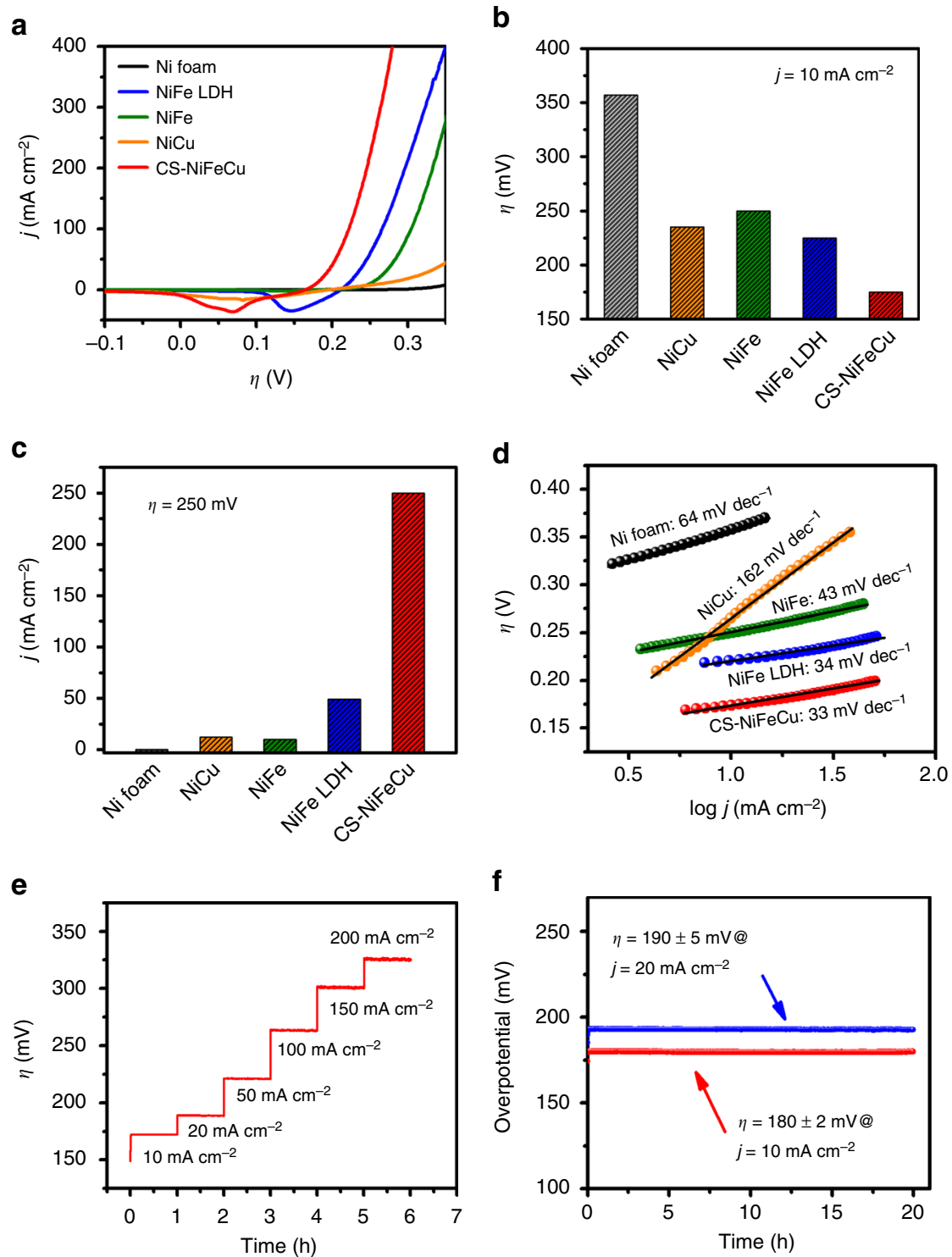

Fig. 4 Electrochemical characterizations for OER. a Polarization curves of CS-NiFeCu, NiFe LDH, NiFe, NiCu electrodes, and nickel foam. b The overpotentials required for $j=10 \mathrm{~mA} \mathrm{~cm}^{-2}$ with different electrodes. c Current densities at $\eta=250 \mathrm{mV}$ with different electrodes. d Tafel plots for nickel foam, $\mathrm{NiCu}, \mathrm{NiFe} \mathrm{LDH}, \mathrm{NiFe}$, and CS-NiFeCu electrodes. e Chronopotentiometric measurements of OER in $1.0 \mathrm{M} \mathrm{KOH}$ at various current densities using CS-NiFeCu as a catalyst. $\mathbf{f}$ Extended chronopotentiometric measurements at $j=10 \mathrm{~mA} \mathrm{~cm}^{-2}$ and $j=20 \mathrm{~mA} \mathrm{~cm}^{-2}$ for $20 \mathrm{~h}$

density of $248 \mathrm{~mA} \mathrm{~cm}^{-2}$, which was $8.5,32.6,26.8$, and 3846 -fold higher than those of NiFe $\mathrm{LDH}, \mathrm{NiFe}, \mathrm{NiCu}$, and nickel foam, respectively. As a matter of fact, the catalytic performance of CS$\mathrm{NiFeCu}$ in $1 \mathrm{M} \mathrm{KOH}$ solution is superior to the previously reported catalysts including NiFe LDH (Supplementary Table 1). So far, NiFe LDH has been generally regarded as the most active OER catalysts in alkaline conditions ${ }^{38}$. To further enhance the activity, the advanced hydrothermal synthesis and electrosynthesis methods have been applied ${ }^{32,} 39$. However, an overpotential of $224 \mathrm{mV}$ for $j=10 \mathrm{~mA} \mathrm{~cm}^{-2}$ was still required, even for the best method $^{39}$. The activity of NiFe LDH was further improved by hybrid approaches with carbon nanomaterials. For example, NiFe hydroxide/graphene superlattice ${ }^{40}$, exfoliated graphene/ $\mathrm{Co}_{0.85} \mathrm{Se} /$ NiFe LDH composites ${ }^{41}$, and r-GO/NiFe $\mathrm{LDH}^{42}$ (r-GO, reduced graphite oxide) reached $j=10 \mathrm{~mA} \mathrm{~cm}{ }^{-2}$ at the overpotentials of 210,203 , and $195 \mathrm{mV}$, respectively. Recently, selenide-derived $\mathrm{NiFe}$ oxide was reported by $\mathrm{Hu}$ et al., which delivers a current density of $10 \mathrm{~mA} \mathrm{~cm}^{-2}$ at an overpotential of $195 \mathrm{mV}^{12}$. In short, our as-prepared $\mathrm{CS}-\mathrm{NiFeCu}$ is now the most-efficient OER catalyst in basic media in terms of the overpotential that required at $10 \mathrm{~mA} \mathrm{~cm}$.2.

The kinetic parameters of the five electrodes were obtained from the corresponding polarization curves by plotting overpotential against $\log (j)$ (Fig. 4d). The as-prepared CS-NiFeCu electrode shows a Tafel slope of $33 \mathrm{mV} \mathrm{dec}{ }^{-1}$, smaller than those of other catalysts $\left(34-162 \mathrm{mV} \mathrm{dec}^{-1}\right)$.

What is noteworthy is that the bimetal-based electrodes show lower activity than $\mathrm{CS}-\mathrm{NiFeCu}$ (Fig. $4 \mathrm{a}-\mathrm{d}$ ). These results indicate that the outstanding activity of CS-NiFeCu is based on the three indispensable elementals rather than any two of them. The preparation of $\mathrm{CuFe}$ under the same electrodeposited conditions, but without the participation of $\mathrm{Ni}$, was not successful (Supplementary Fig. 13 and Supplementary Note 4), indicating that $\mathrm{Ni}$ promoted the co-electrodeposition of $\mathrm{Fe}$ and $\mathrm{Cu}$ (more details of electrodeposition mechanism, see Supplementary Fig. 1 and Supplementary Note 1).

In order to test the steady-state activity and durability of CS$\mathrm{NiFeCu}$, multiple current steps of chronopotentiometry 
a

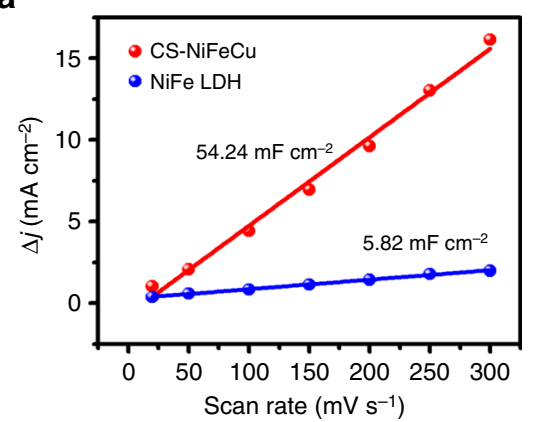

C

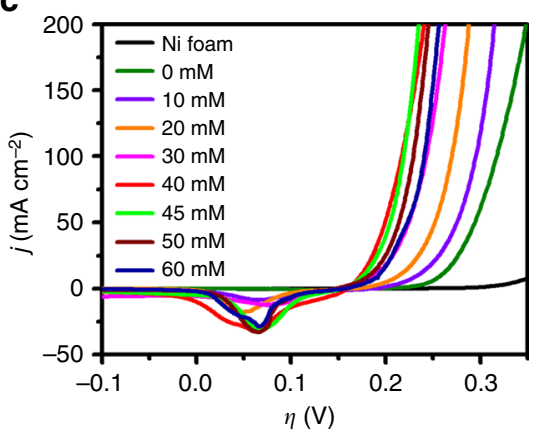

b

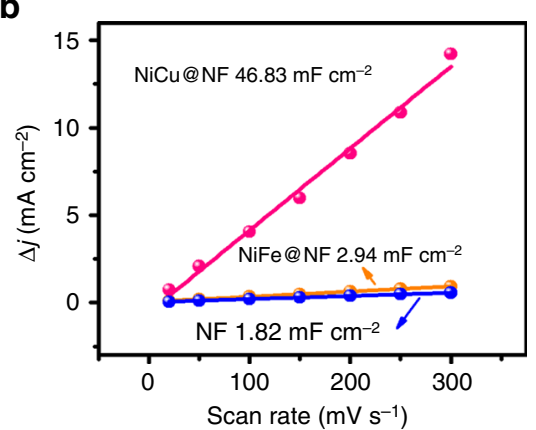

d

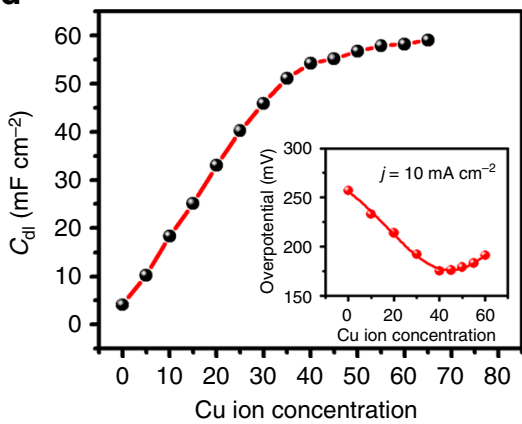

Fig. 5 Contributing factors to the electrochemically active surface area. a Capacitive $j$ vs scan rate for CS-NiFeCu and NiFe LDH anodes. b Capacitive $j$ vs scan rate for $\mathrm{NiCu}$ and $\mathrm{NiFe}$ and $\mathrm{Ni}$ anodes. For $\mathbf{a}$ and $\mathbf{b}$, the linear slope is equivalent to twice of the double-layer capacitance $\mathrm{C}_{\mathrm{d}}$. $\mathbf{c}$ Polarization curves of CS-NiFeCux electrodes. CS-NiFeCux electrodes are prepared in same method as CS-NiFeCu with constant concentration of $\mathrm{Ni}^{2+}$ ( 80 mM) and Fe ${ }^{3+}$ (25 $\mathrm{mM})$, and various concentrations of $\mathrm{Cu}^{2+}(0-60 \mathrm{mM})$ in the electrodeposited electrolytes. $\mathbf{d} C_{\mathrm{dl}}$ of $\mathrm{CS}-\mathrm{NiFeCux}$ anodes. Inset, overpotential required for $j=$ $10 \mathrm{~mA} \mathrm{~cm}^{-2}$

experiments were conducted in $1 \mathrm{M} \mathrm{KOH}$. As shown in Fig. 4e, the corresponding change of applied potentials was profiled when the catalytic current density was increased from 10 to $200 \mathrm{~mA} \mathrm{~cm}$ -2 . Beginning with $10 \mathrm{~mA} \mathrm{~cm}^{-2}$, the overpotential rapidly levels off at $180 \mathrm{mV}$ and remains constant for the following $1 \mathrm{~h}$. Further increase the multiple current steps leads to the overpotentials persisted constantly at a higher value than that at $10 \mathrm{~mA} \mathrm{~cm}{ }^{-2}$. It is noticed that the rough line shown for higher currents than 50 $\mathrm{mA} \mathrm{cm}{ }^{-2}$ is due to the bubble formation during water oxidation reactions. Furthermore, the durability of the $\mathrm{CS}-\mathrm{NiFeCu}$ anode during water oxidation was tested at a constant current density of 10 and $20 \mathrm{~mA} \mathrm{~cm}^{-2}$ for $20 \mathrm{~h}$. As shown in Fig. $4 \mathrm{f}$, the overpotential remained at $180 \pm 2 \mathrm{mV}$ during $20 \mathrm{~h}$ to keep a current density of $10 \mathrm{~mA} \mathrm{~cm}^{-2}$. The same behavior was observed at $20 \mathrm{~mA} \mathrm{~cm}^{-2}$ with an applied overpotential of $190 \pm 5 \mathrm{mV}$. After 20 hours electrolysis, the amount of generated oxygen gas was measured in addition to the recorded current and charge, which were used for the calculation of the Faradaic efficiency ${ }^{10,16}$. The Faradaic efficiencies of $93 \%$ and $98 \%$ were obtained at $j=10$ and $20 \mathrm{~mA} \mathrm{~cm}^{-2}$, respectively (Supplementary Fig. 14), indicating that the accumulated charge was almost consumed on water oxidation. These responses demonstrate the excellent catalytic activity, mass transport properties, and intrinsic robustness of the $\mathrm{CS}-\mathrm{NiFeCu}$ electrode for prolonged electrolysis upon water oxidation.

\section{Discussion}

ECSA is an influential factor for OER catalysts. An increase of ECSA normally leads to the enlargement of the active sites and results in the enhancement of catalytic performance ${ }^{10,12,16}$. Herein, we compare the ECSA of each electrode, which was obtained from cyclic voltammetry (CV) curves for direct comparison (Fig. 5a). In details, by plotting the $\Delta j\left(\mid j_{\text {charge }}-j_{\text {off }}\right.$ chargel) at Faradaic silence potential range against the scan rates, the linear slope is obtained, which is a positive correlation with the double-layer capacitance $\left(C_{\mathrm{dl}}\right)$, and been used to represent the corresponding $\mathrm{ECSA}^{12,16}$. It is important to note that CS-NiFeCu has dramatically higher ECSA comparing with NiFe LDH. As shown in Fig. $5 \mathrm{a}$, the linear slope $\left(C_{\mathrm{dl}}\right)$ of $\mathrm{CS}-\mathrm{NiFeCu}$ electrode has a value of $54.24 \mathrm{mF} \mathrm{cm}{ }^{-2}, 9.3$-fold higher than that of NiFe $\mathrm{LDH}$ under the same conditions. The significantly high ECSA of $\mathrm{CS}-\mathrm{NiFeCu}$ might be attributed to the porous oxide shells, which were created during dealloying process.

In order to distinguish the structural contribution of each element, the double-layer capacitance $\left(C_{\mathrm{dl}}\right)$ of $\mathrm{NiFe}$ and $\mathrm{NiCu}$ electrodes were collected. $\mathrm{NiCu}$ shows the $C_{\mathrm{dl}}$ value of $46.83 \mathrm{mF}$ $\mathrm{cm}^{-2}$ close to CS-NiFeCu, which is $\sim 16$-fold of $\mathrm{NiFe}$ and 26 -fold of $\mathrm{Ni}$ foam (Fig. 5b). This evidence indicated that the high ECSA of $\mathrm{CS}-\mathrm{NiFeCu}$ was mainly based on $\mathrm{NiCu}$ rather than $\mathrm{NiFe}$. Further detail effect of $\mathrm{Cu}$ toward the ECSA in CS-NiFeCu $\mathrm{x}_{\mathrm{x}}$ was detected by tuning its content variation in the film (Fig. $5 c, d$ ). As shown in Fig. $5 \mathrm{~d}$, the $C_{\mathrm{dl}}$ of $\mathrm{CS}-\mathrm{NiFeCu}_{\mathrm{x}}$ was enlarged with the increase of $\mathrm{Cu}$ ion concentration in the electrodeposited electrolytes. The best catalyst for OER was obtained at the concentration of $40 \mathrm{mM}\left(\mathrm{Cu}^{2+}\right)$ (Fig. $5 \mathrm{c}$ and Supplementary Fig. 15), which leads to the formation of an alloy with an atomic ratio of $\mathrm{Ni}: \mathrm{Fe}: \mathrm{Cu}=10: 1: 21$. Further enhancing the content of $\mathrm{Cu}$ in the electrodeposited film by increasing the concentration of $\mathrm{Cu}^{2+}$ in the electrodeposited electrolyte lead to a mild decrease in activity, which may result from the excessively loose and friable structure.

In order to investigate the intrinsic activity of each electrode, the polarization curves of $\mathrm{CS}-\mathrm{NiFeCu}, \mathrm{NiFe} \mathrm{LDH}, \mathrm{NiFe}, \mathrm{NiCu}$, and Ni foam are normalized to ECSA, respectively (Supplementary Fig. 16). The normalized CS-NiFeCu curve achieves a $1 \mathrm{~mA}$ $\mathrm{cm}^{-2}$ current density at $\eta=185 \mathrm{mV}$, while $\mathrm{NiFe} \mathrm{LDH}, \mathrm{NiFe}$, 
a

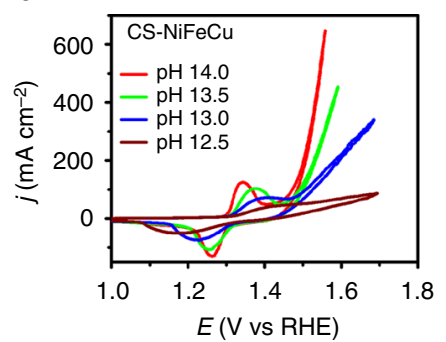

b

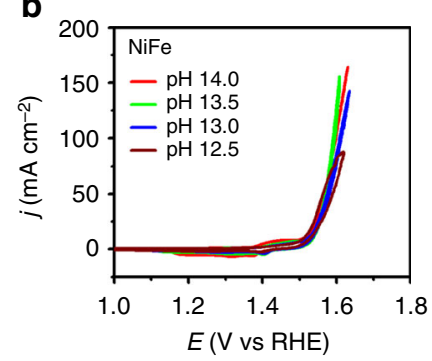

c

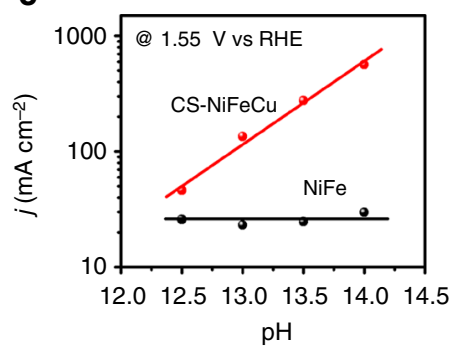

Fig. $6 \mathrm{pH}$-dependent $\mathrm{OER}$ activity on the $\mathrm{RHE}$ scale. a, b Cyclic voltammetry measurements from $\mathrm{O}_{2}-\mathrm{saturated} 0.032 \mathrm{M} \mathrm{KOH}$ ( $\mathrm{pH} 12.5$ ) to $1 \mathrm{M} \mathrm{KOH}$ (pH 14) recorded at $10 \mathrm{mV} \mathrm{s}^{-1}$ with CS-NiFeCu and NiFe electrodes. c Specific OER activity (current density) at $1.55 \mathrm{~V}$ vs RHE after iR correction as a function of $\mathrm{pH}$

$\mathrm{NiCu}$, and $\mathrm{Ni}$ foam require the overpotentials of $228,260,300$, and $320 \mathrm{mV}$ to reach the same current density. The overpotential (@ $j_{\text {normalized }}=1 \mathrm{~mA} \mathrm{~cm}^{-2}$ ) of $\mathrm{CS}-\mathrm{NiFeCu}$ for OER was cathodically shift by $43 \mathrm{mV}$ compared with $\mathrm{NiFe} \mathrm{LDH}$ and $75 \mathrm{mV}$ compared with $\mathrm{NiFe}$ (Fig. $5 \mathrm{c}$ ). These results indicated that CS$\mathrm{NiFeCu}$ has the optimal intrinsic activity compared with other four electrodes.

So far, two fundamentally different mechanisms were reported to understand how materials catalyze the $\mathrm{OER}^{43}$. Based on the relationship between $\mathrm{pH}$ values and OER activity, the OER mechanisms were divided into two types. First, the four concerted proton-electron transfer pathway with $\mathrm{pH}$-independent activity on the reversible hydrogen electrode (RHE) scale, where the catalytic performance was contributed to the surface metal-ion centers $^{44}$. Second, the four non-concerted proton-electron transfer mechanism with $\mathrm{pH}$-dependent activity on the RHE scale, where the catalytic performance was contributed to the bulk material, including the surface metal-ion centers and the lattice oxygen $^{43}$.

$\mathrm{CV}$ measurements recorded from $0.032 \mathrm{M}(\mathrm{pH} 12.5)$ to $1 \mathrm{M}$ $\mathrm{KOH}$ were used to investigate the relationship between $\mathrm{pH}$ values and OER activity (Fig. 6), that provide valuable information for studying the catalytic mechanism ${ }^{43}$. RHE scale was used as the reference to assure that the OER overpotential remained identical across different values of $\mathrm{pH}$ with respect to the equilibrium $\mathrm{O}_{2} /$ $\mathrm{H}_{2} \mathrm{O}$ redox potential ${ }^{45}$. The $\mathrm{CV}$ of $\mathrm{CS}-\mathrm{NiFeCu}$ shows an oxidation peak current density as large as $126 \mathrm{~mA} \mathrm{~cm}^{-2}$ at $1.35 \mathrm{~V}$, corresponding to the $\mathrm{Ni}^{2+} / \mathrm{Ni}^{3+}$ oxidation in $1 \mathrm{M} \mathrm{KOH}$, which is $\sim 10$ times as that of NiFe LDH supported with nickel foam ${ }^{32}$. This extremely high peak current density is attributed to the large ECSA of CS-NiFeCu, which is 9.3-fold higher than that of NiFe LDH. As shown in Fig. 6a, the OER activity of CS-NiFeCu at 1.55 $\mathrm{V}$ vs RHE exhibits $\mathrm{pH}$-dependent OER activity on RHE scale (Fig. 6a, c), hinting that non-concerted proton-electron transfers engage in catalyzing the $\mathrm{OER}^{46}$, in which the rate-limiting step is either a proton transfer step or preceded by acid/base equilibrium. With this mechanism, the high activity of $\mathrm{CS}-\mathrm{NiFeCu}$ can be contributed to bulk oxide shell, including the surface metal-ion centers and the lattice oxygen ${ }^{43}$. Without the participation of copper, dimetal-based $\mathrm{NiFe}$ electrode show $\mathrm{pH}$-independent of OER activity on RHE scale (Fig. $6 \mathrm{~b}, \mathrm{c}$ ). These results indicate that the NiFe electrode catalyzed the OER with concerted protonelectron transfer steps, where the activity is determined by the reaction intermediate binding strengths on surfaces ${ }^{44}$. Above research results indicated that the participation of $\mathrm{Cu}$ into $\mathrm{NiFe}$ led to a fundamentally different mechanism for the OER. In addition to high ECSA factor, it is the bulk material-based mechanism, which was triggered by the participation of $\mathrm{Cu}$, leads to the OER activity enhancement on $\mathrm{CS}-\mathrm{NiFeCu}$ electrode.

In order to get more subtle electrochemical signals, nickel microelectrodes with a surface area of $0.0078 \mathrm{~cm}^{2}(d=0.1 \mathrm{~cm})$ were used as the substrates. The $\mathrm{CV}$ s for $\mathrm{Ni}$ and $\mathrm{NiFe}$ electrodes in $\mathrm{KOH}$ exhibit two primary features, a redox couple at $1.38 \mathrm{~V}$ and $1.41 \mathrm{~V}$ vs RHE and an oxidation current visible at overpotentials greater than $1.45 \mathrm{~V}$ vs RHE (Supplementary Fig. 17a). The redox peaks are attributed to the transformation between $\mathrm{Ni}^{2+}$ and $\mathrm{Ni}^{3+47,48}$. Oxidation currents at higher potentials are due to oxygen evolution. $\mathrm{CVs}$ for $\mathrm{CS}-\mathrm{NiFeCu}_{\mathrm{x}}$ series differ noticeably in their $\mathrm{Ni}^{2+} / \mathrm{Ni}^{3+}$ redox characteristics (Supplementary Fig. 17b). As more $\mathrm{Cu}$ is incorporated into the NiFe-based film, the $\mathrm{Ni}^{2+} / \mathrm{Ni}^{3+}$ redox peaks were cathodically shifted to 1.33 $\mathrm{V}$ vs RHE, a new $\mathrm{Ni}^{2+} / \mathrm{Ni}^{3+}$ oxidation peak was generated at 1.35 $\mathrm{V}$ vs RHE, which further enhanced with the increase of $\mathrm{Cu}$ amount in the electrodeposited electrolyte (Supplementary Fig. 17b). The $\mathrm{Ni}^{2+} / \mathrm{Ni}^{3+}$ oxidation peak of the as-prepared CS$\mathrm{NiFeCu}$ shifted to a negative potential by as much as $50 \mathrm{mV}$ relative to that for $\mathrm{NiFe}$. This result suggests that the electrochemical oxidation of $\mathrm{Ni}^{2+}$ to $\mathrm{Ni}^{3+}$ is facilitated by the presence of $\mathrm{Cu}$. The $\mathrm{CV}$ for $\mathrm{CS}-\mathrm{NiFeCu}$ shows two adjacent $\mathrm{Ni}^{2+} / \mathrm{Ni}^{3+}$ oxidation peaks, indicated that two kinds of electroactive components exist in the oxide shell of CS-NiFeCu. The peak at $1.35 \mathrm{~V}$ vs RHE is corresponding to $\mathrm{NiFeCu}$ oxide and the peak at $1.38 \mathrm{~V}$ vs $\mathrm{RHE}$ is corresponding to $\mathrm{NiFe}$ oxide. Both $\mathrm{NiFeCu}$ oxide and $\mathrm{NiFe}$ oxide are active for OER. NiFeCu oxide, characterized with a more negative $\mathrm{Ni}^{2+} / \mathrm{Ni}^{3+}$ oxidation peak, has the pivotal role to reduce the overpotential for OER.

As well known, the doping of $\mathrm{Fe}$ in Ni-based catalysts can enhance the catalytic activity ${ }^{42,49}$. To verify the role of Fe in CS$\mathrm{NiFeCu}$, electrodes with a constant concentration of $\mathrm{NiCu}$ and a variable concentration of $\mathrm{Fe}$ were prepared by adjusting the $\mathrm{Fe}$ ion concentration in the electrodeposited electrolytes. With the increase of $\mathrm{Fe}$ ion concentration, polarization curves of CS$\mathrm{NiFe}_{\mathrm{x}} \mathrm{Cu}$ show obviously enhancement in catalytic performance (Fig. 7a, b). The current densities at $\eta=250 \mathrm{mV}$ were increased from $\sim 20-200 \mathrm{~mA} \mathrm{~cm}^{-2}$. As shown in Fig. 7a, the activity of CS$\mathrm{NiFe}_{\mathrm{x}} \mathrm{Cu}$ increases with $\mathrm{Fe}$ content, further confirmed that the $\mathrm{NiFe}$-based components are the active sites for water oxidation reaction ${ }^{9}$. ECSAs of $\mathrm{CS}-\mathrm{NiFe}_{\mathrm{x}} \mathrm{Cu}$ anodes were further examined in details, as shown in Fig. 7c. The $C_{\mathrm{dl}}$ of $\mathrm{CS}-\mathrm{NiFe}_{\mathrm{x}} \mathrm{Cu}$ electrodes with different Fe content distributed in the range of $50 \pm 5 \mathrm{mF} \mathrm{cm}$ -2 (Fig. 7c). No obvious change was observed with the increase of Fe content, indicated that the ECSA of CS-NiFe $\mathrm{x}_{\mathrm{x}} \mathrm{Cu}$ electrodes is independent of Fe. This result ruled out the contribution of Fe to the ECSA factor.

Tafel slope analysis was used to understand the influence of $\mathrm{Fe}$ content on the intrinsic kinetics of $\mathrm{CS}-\mathrm{NiFe}_{\mathrm{x}} \mathrm{Cu}$. As shown in Fig. $7 \mathrm{~d}$ and Supplementary Fig. 18, the Tafel slope is crucially affected by $\mathrm{Fe}$ content. $\mathrm{NiCu}$ electrode without $\mathrm{Fe}$ shows a Tafel slope of $164 \mathrm{mV} \mathrm{dec}^{-1}$ in $1.0 \mathrm{M} \mathrm{KOH}$. The Tafel slopes for OER reduced to the smallest $33 \mathrm{mV} \mathrm{dec}^{-1}$ when the $\mathrm{Fe}^{3+}$ concentrations were increased from 0 to $25 \mathrm{mM}$, while the Fe:Ni atomic ratio in the electrodeposited film was increased from 0 to $10: 1$. 
a

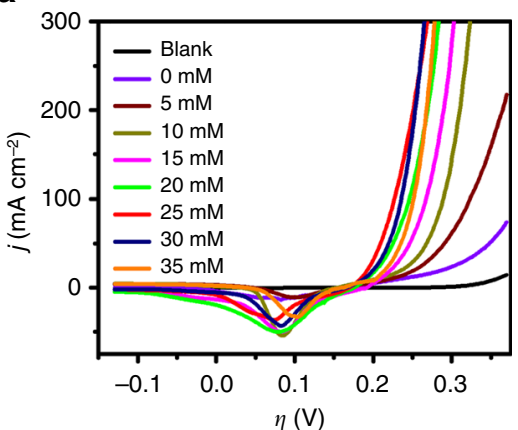

C

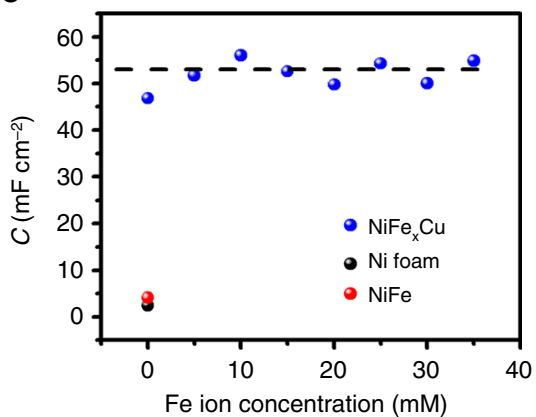

b

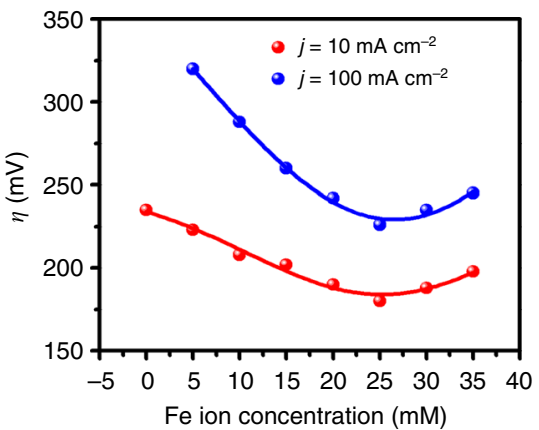

d

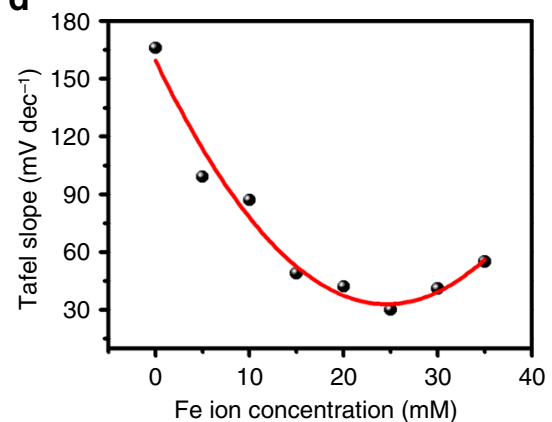

Fig. 7 Contributing factors to the kinetics. a Polarization curves of CS-NiFexCu anodes. b Overpotentials required for $j=10$ and $100 \mathrm{~mA} \mathrm{~cm}{ }^{-2}$ with CS$\mathrm{NiFe}_{x} \mathrm{Cu}$ anodes in $1 \mathrm{M} \mathrm{KOH}$. $\mathbf{c} \mathrm{C}_{d l}$ of CS-NiFexCu anodes. $\mathbf{d}$ Tafel slopes of CS-NiFe ${ }_{x} \mathrm{Cu}$ in $1 \mathrm{M} \mathrm{KOH}$. CS-NiFe $\mathrm{Cu}_{\mathrm{x}}$ electrodes are prepared in the electrodeposited electrolytes with concentration of $\mathrm{Ni}^{2+}(80 \mathrm{mM}), \mathrm{Cu}^{2+}(40 \mathrm{mM})$, and variable concentration of $\mathrm{Fe}^{3+}(0-35 \mathrm{mM})$ concentrations

However, further increasing the amount of $\mathrm{Fe}$ in $\mathrm{CS}-\mathrm{NiFe}_{\mathrm{x}} \mathrm{Cu}$ electrodes led to a moderate decrease of Tafel slope values. When the $\mathrm{Fe}^{3+}$ concentrations were increased from $25 \mathrm{mM}$ to $35 \mathrm{mM}$, the $\mathrm{Fe}: \mathrm{Ni}$ atomic ratio in the electrodeposited film increased from 0.1 to 0.14 , and the corresponding Tafel slopes decrease from 34.0 to $44 \mathrm{mV} \mathrm{dec}^{-1}$. This result strongly supports the conclusion that doping $\mathrm{Fe}$ into $\mathrm{NiCu}$ based materials can adjust the catalytic property by tuning the intrinsic kinetics. Furthermore, it is important to notice that there is always an optimal proportion that leads to the best performance. This result is slightly different from the previous studies that the $\mathrm{NiFeOx}$ activity varied marginally when the $\mathrm{Fe}: \mathrm{Ni}$ atomic ratio was adjusted from 0.1 to $0.55^{42}, 49$. The relationship between the optimal proportion and catalytic activity was still not clear and needs more investigation.

In summary, using electrodeposited $\mathrm{NiFeCu}$ as a precursor, we have shown that the tri-metal-based alloy can be converted into the CS metal/metal oxide catalyst CS-NiFeCu for OER. The high catalytic performance of $\mathrm{CS}-\mathrm{NiFeCu}$ for water oxidation is attributed to the synergistic effect of $\mathrm{Ni}, \mathrm{Fe}$, and $\mathrm{Cu}$. The relative amounts of the three elements in $\mathrm{CS}-\mathrm{NiFeCu}$ electrode play a decisive role by enhancing the ECSA and intrinsic catalytic activity. A current density of $10 \mathrm{~mA} \mathrm{~cm}^{-2}$ is obtained at an overpotential of only $180 \mathrm{mV}$ in $1 \mathrm{M} \mathrm{KOH}$ alkaline solution using $\mathrm{CS}-\mathrm{NiFeCu}$ as working electrode, which is one of the most active OER catalysts reported to date. The nano-synthesis approach described in this work may be applicable to the development of other alloy-based nanomaterials as catalysts for OER and beyond.

\section{Methods}

Preparation of CS-NiFeCu electrode. The CS-NiFeCu anodes were prepared through two steps: (i) NiFeCu parent alloy was grown on nickel foam (thickness: $1.6 \mathrm{~mm}$, bulk density: $0.45 \mathrm{~g} \mathrm{~cm}^{-3}$, Goodfellow) via electrodeposition; (ii) parent alloys were converted into $\mathrm{CS}-\mathrm{NiFeCu}$ anode via a dealloying treatment (more details of electrodeposition mechanism, see Supplementary Fig. 1). Before electrodeposition, the nickel foam was sonicated in concentrated $\mathrm{HCl}(37 \%)$ solution for $5 \mathrm{~min}$ to remove the $\mathrm{NiO}_{\mathrm{x}}$ surface layer, and subsequently rinsed with water and acetone, then allowed to dry in air. The electrodeposition was carried out with a standard three-electrode electrochemical cell containing nickel foam as the working electrode, a platinum foil $\left(4 \mathrm{~cm}^{2}\right)$ auxiliary electrode and an $\mathrm{Ag} / \mathrm{AgCl}(3 \mathrm{M} \mathrm{KCl})$ reference electrode. The electrolyte solution consisted of $80 \mathrm{mM} \mathrm{NiCl}_{2} \cdot 6 \mathrm{H}_{2} \mathrm{O}, 0-25$ $\mathrm{mM} \mathrm{Fe}\left(\mathrm{NO}_{3}\right)_{2} \cdot 9 \mathrm{H}_{2} \mathrm{O}, 0-40 \mathrm{mM} \mathrm{Cu}\left(\mathrm{SO}_{4}\right) \cdot 5 \mathrm{H}_{2} \mathrm{O}, 0.2 \mathrm{M}$ Sodium citrate tribasic dehydrate $\left(\mathrm{Na}_{3} \mathrm{C}_{6} \mathrm{H}_{5} \mathrm{O}_{7} \cdot 2 \mathrm{H}_{2} \mathrm{O}\right), 0.45 \mathrm{M}$ ammonium sulfate $\left(\left(\mathrm{NH}_{4}\right)_{2} \mathrm{SO}_{4}\right)$ and 0.55 $\mathrm{M}$ sodium hypophosphite monohydrate $\left(\mathrm{NaPO}_{2} \mathrm{H}_{2} \cdot \mathrm{H}_{2} \mathrm{O}\right)$. The electrodeposition solution $\mathrm{pH}$ values of were adjusted to 10.0 by $10 \mathrm{M} \mathrm{NaOH}$ solution. To optimize the deposited $\mathrm{NiFeCu}$ alloy compositions, the concentrations of $\mathrm{Ni}^{2+}, \mathrm{Fe}^{3+}$, and $\mathrm{Cu}^{2+}$ in electrolyte were tuned to systematically varied the Ni:Fe:Cu atomic ratio in the electrodeposited parent alloy film. We found that an 80:25:40 molar ratio of $\mathrm{Ni}^{2}$ ${ }^{+}, \mathrm{Fe}^{3+}$, and $\mathrm{Cu}^{2+}$ provides the $\mathrm{CS}-\mathrm{NiFeCu}$ electrode with the highest catalytic OER activity. The CS-NiFeCu in this work was prepared with the 80:25:40 molar ratio of $\mathrm{Ni}^{2+}, \mathrm{Fe}^{3+}$, and $\mathrm{Cu}^{2+}$. Typically, the $\mathrm{NiFeCu}$ alloy film was prepared though controlled potential electrolysis at $-1.1 \mathrm{~V}$ vs $\mathrm{Ag} / \mathrm{AgCl}$ at room temperature using a $\mathrm{CH}$ Instruments $660 \mathrm{E}$ potentiostat. The optimized $\mathrm{NiFeCu}$ alloy deposition time has been determined to be $1 \mathrm{~h}$. After deposition, the alloy was carefully rinsed with water and acetone. The dealloying step was carried out in $3 \mathrm{M} \mathrm{KOH}$ with a controlled current density of $200 \mathrm{~mA} \mathrm{~cm}^{-2}$ for $10 \mathrm{~h}$. After dealloying, the CS-NiFeCu anode was withdrawn carefully from the electrolyte, rinsed with water and acetone, and then allowed to dry in air.

Physical characterization. XPS characterization was acquired with a Thermo VG ESCALAB250 surface analysis system. Powder XRD measurement was performed on a X'Pert PANalytical Pro MRD. SEM images and EDX spectra were obtained with a NOVA NanoSEM 450 and JEOL JSM 7401 equipped with EDX system. TEM images and SAED were taken on JEOL JEM2100 TEM.

Soft-XAS. $\mathrm{Ni}, \mathrm{Fe}$, and $\mathrm{Cu} L_{2,3}$-edge and $\mathrm{O} K$-edge soft-XAS of samples were performed at beamline 8-2 of the Stanford Synchrotron Radiation Lightsource (SSRL), SLAC National Accelerator Laboratory, USA. All samples were attached to an aluminum sample holder using double-sided conductive carbon tape. The $L_{2,3^{-}}$ edge spectra were collected at room temperature under ultrahigh vacuum (10-9 Torr) with the incident beam monochromatized using a spherical grating monochromator with $1100 \mathrm{~mm}^{-1}$ ruling, where the exit and entrance slits were set to an intermediate resolution of $0.3 \mathrm{eV}$. All XAS spectra were collected in the TEY method, obtained through the drain current, and corresponding to probing depths of $2-5 \mathrm{~nm}$. The $\mathrm{NiO}, \mathrm{Fe}_{3} \mathrm{O}_{4}, \mathrm{Fe}_{2} \mathrm{O}_{3}$, and $\mathrm{CuO}$ standard powders were applied as ordered directly onto the carbon tape. The spectra were normalized to the incident photon flux measured by a gold grid upstream. The spectra were normalized via a linear background subtraction followed by an intensity normalization (maximum set to 1) for visual comparison. 
Electrochemical characterization. All electrochemical experiments were performed with a $\mathrm{CH}$ Instrument 660E potentiostat. The electrochemical cell containing samples as the working electrode, a platinum foil $\left(4 \mathrm{~cm}^{2}\right)$ auxiliary electrode and BASi $\mathrm{Ag} / \mathrm{AgCl}$ reference electrode. In daily experiments, a $\mathrm{Hg} / \mathrm{HgO}(1 \mathrm{M}$ $\mathrm{KOH}$, Tjaida) electrode was used as a standard reference $\left(E_{\mathrm{Hg} / \mathrm{HgO}}=0.098 \mathrm{~V}\right.$ vs $\mathrm{RHE}$ ). When $\mathrm{Ag} / \mathrm{AgCl}$ electrode was used as a reference electrode in alkaline aqueous electrolytes, the potential differences $(\Delta E)$ between $\mathrm{Ag} / \mathrm{AgCl}$ electrode and $\mathrm{Hg} / \mathrm{HgO}$ electrode in the same alkaline electrolyte were recorded for calibration $\left(E_{\mathrm{Hg} / \mathrm{HgO}=}^{\mathrm{O}} E_{\mathrm{Ag} / \mathrm{AgCl}}^{\mathrm{O}}-|\Delta E|=0.098 \mathrm{~V}\right.$ vs RHE$)$. The reference electrodes were calibrated by measuring the RHE potential using a Pt electrode under $\mathrm{H}_{2}$ atmosphere once a week. In $1 \mathrm{M} \mathrm{KOH}$, all potentials measured were converted to the overpotential reference scale using the Nernst equation: $\eta=E_{\mathrm{Ag} / \mathrm{AgCl}}-0.221 \mathrm{~V}$. Potentials converted to RHE reference scale via the Nernst equation: $E_{\mathrm{RHE}}=E_{\mathrm{Ag} / \mathrm{AgCl}}+0.059$ $\mathrm{pH}+E_{\mathrm{Ag} / \mathrm{AgCl}}^{\mathrm{O}}$. The as-prepared anodes were fixed to $0.5 \mathrm{~cm}^{2}$ by using epoxy glue. Platinum foil $\left(4 \mathrm{~cm}^{2}\right)$ was purchased from Tjaida and used as counter electrode. The internal resistance between the reference and working electrodes $(R \mathrm{u})$ has been measured by automatic current interrupt method and impedance method. In automatic measurements, the value of $R \mathrm{u}$ was in the range of $0.7-0.9 \Omega$, which is small and similar to the impedance data $(0.75-0.78 \Omega)$ (Supplementary Fig. 19). In this paper, the $i R$ compensation was performed by automatic current interrupt method with a value of $75 \% \times R \mathrm{u}$ through the $\mathrm{CH}$ instrument $660 \mathrm{E}$ potentiostat. In order to provide reliable electrochemical data and avoid the overlap between $\mathrm{Ni}^{2}$ ${ }^{+} / \mathrm{Ni}^{3+}$ oxidation and OER, polarization curves were recorded from high initial potentials to low final potentials with a $5 \mathrm{mV} \mathrm{s}^{-1}$ scan rate (more details, see Supplementary Fig. 20 and Supplementary Note 5). Before sweep, the as-prepared anodes were activated by a chronopotentiometry scan with the $50 \mathrm{~mA} \mathrm{~cm}{ }^{-2}$ current density for $2 \mathrm{~h}$. Tafel slopes were calculated using the Polarization curves by plotting overpotential against $\log ($ current density). The steady-state activity and long-term activity were evaluated by chronopotentiometry measurements. The ECSA was determined by measuring the capacitive current associated with doublelayer charging from the scan rate $\mathrm{CV}$-dependence. Here, the $\mathrm{CV}$ potential window was 0.3 to $-0.5 \mathrm{vs} \mathrm{Ag} / \mathrm{AgCl}$. The scan rates were $20,50,100,250,200,250$, and 300 $\mathrm{mV} \mathrm{s}^{-1}$. The double-layer capacitance $\left(C_{\mathrm{d} 1}\right)$ was estimated $\Delta j=\left(j_{\text {charge }}-j_{\text {off charge }}\right)$ at $-0.5 \mathrm{~V}$ vs $\mathrm{Ag} / \mathrm{AgCl}$ against the scan rate. The liner slop is twice of the double-layer capacitance $C_{\mathrm{dl}}$. The $\mathrm{O}_{2}$ measurements were obtained by gas chromatography.

Data availability. The data that support the findings of this study are available within the article (and its Supplementary Information files) and from the corresponding authors upon reasonable request.

Received: 8 June 2017 Accepted: 29 November 2017

Published online: 26 January 2018

\section{References}

1. Lewis, N. S. \& Nocera, D. G. Powering the planet: chemical challenges in solar energy utilization. Proc. Natl Acad. Sci. USA 103, 15729-15735 (2006).

2. Dau, H. et al. The mechanism of water oxidation: from electrolysis via homogeneous to biological catalysis. ChemCatChem 2, 724-761 (2010).

3. Singh, A. \& Spiccia, L. Water oxidation catalysts based on abundant first-row transition metals. Coord. Chem. Rev. 257, 2607-2622 (2013).

4. Galan-Mascaros, J. R. Water oxidation at electrodes modified with earth abundant transition-metal catalysts. ChemElectroChem 2, 37-50 (2015).

5. Hunter, B. M., Gray, H. B. \& Müller, A. M. Earth-abundant heterogeneous water oxidation catalysts. Chem. Rev. 116, 1420-14136 (2016).

6. Stern, L. A., Feng, L. G., Song, F. \& Hu, X. L. $\mathrm{Ni}_{2} \mathrm{P}$ as a Janus catalyst for water splitting: the oxygen evolution activity of Ni2P nanoparticles. Energy Environ. Sci. 8, 2347-2351 (2015)

7. Ryu, J., Jung, N., Jang, J. H., Kim, H. J. \& Yoo, S. J. In situ transformation of hydrogen-evolving CoP nanoparticles: toward efficient oxygen evolution catalysts bearing dispersed morphologies with Co-oxo/hydroxo molecular units. ACS Catal. 5, 4066-4074 (2015).

8. Wang, P., Song, F., Amal, R., Ng, Y. H. \& Hu, X. Efficient water splitting catalyzed by cobalt phosphide-based nanoneedle arrays supported on carbon cloth. ChemSusChem 9, 472-477 (2016)

9. Louie, M. W. \& Bell, A. T. An investigation of thin-film Ni-Fe oxide catalysts for the electrochemical evolution of oxygen. J. Am. Chem. Soc. 135, 12329-12337 (2013).

10. Detsi, E. et al. Mesoporous $\mathrm{Ni}_{60} \mathrm{Fe}_{30} \mathrm{Mn}_{10}$-alloy based metal/metal oxide composite thick films as highly active and robust oxygen evolution catalysts. Energy Environ. Sci. 9, 540-549 (2016).

11. Chen, W. et al. In situ electrochemical oxidation tuning of transition metal disulfides to oxides for enhanced water oxidation. ACS Cent. Sci. 1, 244-251 (2015)
12. Xu, X., Song, F. \& Hu, X. A nickel iron diselenide-derived efficient oxygenevolution catalyst. Nat. Commun. 7, 12324 (2016).

13. Hunter, B. M. et al. Highly active mixed-metal nanosheet water oxidation catalysts made by pulsed-laser ablation in liquids. J. Am. Chem. Soc. 136, 13118-13121 (2014).

14. Gerken, J. B., Shaner, S. E., Masse, R. C., Porubsky, N. J. \& Stahl, S. S. A survey of diverse earth abundant oxygen evolution electrocatalysts showing enhanced activity from Ni-Fe oxides containing a third metal. Energy Environ. Sci. 7, 2376-2382 (2014).

15. Gong, M. et al. An advanced Ni-Fe layered double hydroxide electrocatalyst for water oxidation. J. Am. Chem. Soc. 135, 8452-8455 (2013).

16. Fan, K. et al. Nickel-vanadium monolayer double hydroxide for efficient electrochemical water oxidation. Nat. Commun. 7, 11981 (2016).

17. Zhang, B. et al. Homogeneously dispersed multimetal oxygen-evolving catalysts. Science 352, 333-337 (2016).

18. Gong, M. \& Dai, H. A mini review of NiFe-based materials as highly active oxygen evolution reaction electrocatalysts. Nano Res. 8, 23-39 (2015).

19. Kim, K. H., Zheng, J. Y., Shin, W. \& Kang, Y. S. Preparation of dendritic NiFe films by electrodeposition for oxygen evolution. RSC Adv. 2, 4759-4767 (2012).

20. Goranova, D., Avdeev, G. \& Rashkov, R. Electrodeposition and characterization of Ni-Cu alloys. Surf. Coat. Technol. 240, 204-210 (2014).

21. Alper, M., Kockar, H., Safak, M. \& Baykull, M. C. Comparison of Ni-Cu alloy films electrodeposited at low and high pH levels. J. Alloys Compd. 453, 15-19 (2008).

22. Liu, X., Cui, S., Qian, M., Sun, Z. \& Du, P. In situ generated highly active copper oxide catalysts for the oxygen evolution reaction at low overpotential in alkaline solutions. Chem. Comm. 52, 5546-5549 (2016).

23. Kear, G., Barker, B. D. \& Walsh, F. C. Electrochemical corrosion of unalloyed copper in chloride media-a critical review. Corros. Sci. 46, 109-135 (2004).

24. Sun, L., Chien, C.-L. \& Searson, P. C. Fabrication of nanoporous nickel by electrochemical dealloying. Chem. Mater. 16, 3125-3129 (2004).

25. Burke, L. D., Ahern, M. J. G. \& Ryan, T. G. An investigation of the anodic behavior of copper and its anodically produced oxides in aqueous solutions of high pH. J. Electrochem. Soc. 137, 553-561 (1990).

26. Detsi, E., Schootbrugge, M. V. D., Punzhin, S., Onck, P. R. \& De Hosson, J. T. M. On tuning the morphology of nanoporous gold. Scr. Mater. 64, 319-322 (2011).

27. Erlebacher, J., Aziz, M. J., Karma, A., Dimitrov, N. \& Sieradzki, K. Evolution of nanoporosity in dealloying. Nature 410, 450-453 (2001).

28. Detsi, E., Punzhin, S., Rao, J., Onck, P. R. \& De Hosson, J. T. M. Enhanced strain in functional nanoporous gold with a dual microscopic length scale structure. ACS Nano 6, 3734-3744 (2012).

29. Bae, S.-H. et al. Seamlessly conductive 3D nanoarchitecture of core-shell Ni-Co nanowire network for highly efficient oxygen evolution. Adv. Energy Mater. 7, 1601492 (2017)

30. De Chialvo, M. R. G., Marchiano, S. L. \& Arvía, A. J. The mechanism of oxidation of copper in alkaline solutions. J. Appl. Electrochem. 14, 165-175 (1984).

31. Liu, X. et al. Self-supported copper oxide electrocatalyst for water oxidation at low overpotential and confirmation of Its robustness by $\mathrm{Cu} K$-edge X-ray absorption spectroscopy. J. Phys. Chem. C. 120, 831-840 (2016).

32. Lu, X. \& Zhao, C. Electrodeposition of hierarchically structured threedimensional nickel-iron electrodes for efficient oxygen evolution at high current densities. Nat. Commun. 6, 6616 (2015).

33. Van Elp, J., Searle, B. G., Searle, Sawatzky, G. A. \& Sacchi, M. Ligand hole induced symmetry mixing of $\mathrm{d} 8$ states in $\mathrm{Li}_{\mathrm{x}} \mathrm{Ni}_{1-\mathrm{x}} \mathrm{O}$, as observed in $\mathrm{Ni} 2 \mathrm{p}$ x-ray absorption spectroscopy. Solid State Commun. 80, 67-71 (1991).

34. Kim, D. H. et al. Interface electronic structures of $\mathrm{BaTiO}_{3} @ \mathrm{X}$ nanoparticles $\left(\mathrm{X}=\gamma-\mathrm{Fe}_{2} \mathrm{O}_{3}, \mathrm{Fe}_{3} \mathrm{O}_{4}, \alpha-\mathrm{Fe}_{2} \mathrm{O}_{3}\right.$, and $\mathrm{Fe}$ ) investigated by XAS and XMCD. Phys. Rev. B 79, 033402 (2009).

35. Pearce, C. I., Pattrick, R. A. D., Vaughan, D. J., Henderson, C. M. B. \& Van der Laan, G. Copper oxidation state in chalcopyrite: Mixed $\mathrm{Cu}$ d9 and d10 characteristics. Geochim. Cosmochim. Acta 70, 4635-4642 (2006).

36. Gurevich, A. B., Bent, B. E., Teplyakov, A. V. \& Chen, J. G. A NEXAFS investigation of the formation and decomposition of $\mathrm{CuO}$ and $\mathrm{Cu}_{2} \mathrm{O}$ thin films on $\mathrm{Cu}(100)$. Surf. Sci. Rep. 442, L971-L976 (1999).

37. de Groot, F. F. M. et al. Oxygen 1s x-ray-absorption edges of transition-metal oxides. Phys. Rev. B 40, 5715-5723 (1989).

38. Lu, Z. et al. Three-dimensional NiFe layered double hydroxide film for high-efficiency oxygen evolution reaction. Chem. Commun. 50, 6479-6482 (2014).

39. Li, Z. et al. Fast electrosynthesis of Fe-containing layered double hydroxide arrays toward highly efficient electrocatalytic oxidation reactions. Chem. Sci. 6 , 6624-6631 (2015).

40. Ma, W. et al. A superlattice of alternately stacked Ni-Fe hydroxide nanosheets and graphene for efficient splitting of water. ACS Nano 9, 1977-1984 (2015). 
41. Hou, Y. et al. Vertically oriented cobalt selenide/NiFe layered-double-hydroxide nanosheets supported on exfoliated graphene foil: an efficient 3D electrode for overall water splitting. Energy Environ. Sci. 9, 478-483 (2016).

42. Long, X. et al. A strongly coupled graphene and FeNi double hydroxide hybrid as an excellent electrocatalyst for the oxygen evolution reaction. Angew. Chem. Int. Ed. 53, 7584-7588 (2014).

43. Grimaud, A. et al. Activating lattice oxygen redox reactions in metal oxides to catalyse oxygen evolution. Nat. Chem. 9, 457-465 (2017).

44. Koper, M. T. M. Theory of multiple proton-electron transfer reactions and its implications for electrocatalysis. Chem. Sci. 4, 2710-2723 (2013).

45. Giordano, L. et al. pH dependence of OER activity of oxides: current and future perspectives. Catal. Today 262, 2-10 (2016).

46. Matsumoto, Y., Manabe, H. \& Sato, E. Oxygen evolution on $\mathrm{La}_{1-x} \mathrm{Sr}_{x} \mathrm{CoO}_{3}$ electrodes in alkaline solutions. J. Electrochem. Soc. 127, 811-814 (1980).

47. Yeo, B. S. \& Bell, A. T. In situ Raman study of nickel oxide and gold-supported nickel oxide catalysts for the electrochemical evolution of oxygen. J. Phys. Chem. C. 116, 8394-8400 (2012).

48. Cornilsen, B. C., Shan, X. \& Loyselle, P. L. Structural comparison of nickel electrodes and precursor phases. J. Power Sources 29, 453-466 (1990).

49. Trotochaud, L., Young, S. L., Ranney, J. K. \& Boettcher, S. W. Nickel-iron oxyhydroxide oxygen-evolution electrocatalysts: the role of intentional and incidental iron incorporation. J. Am. Chem. Soc. 136, 6744-6753 (2014).

\section{Acknowledgements}

We acknowledge the financial support of this work by Swedish Energy Agency, the Knut \& Alice Wallenberg Foundation, the Swedish Research Council, the National Natural Science Foundation of China $(21120102036,91233201)$ and the National Basic Research Program of China (973 Program, 2014CB239402). L.L. is supported by the Wallenberg Foundation postdoctoral scholarship program, the MAX IV synchrotron radiation facility program. We acknowledge Kristjan Kunnus, Sergey Koroidov, Robert W. Hartsock, Marco E. Reinhart, and Kiryong Hong, and Kelly Gaffney from SLAC National Accelerator Laboratory for the discussions. Use of the Stanford Synchrotron Radiation Lightsource, SLAC National Accelerator Laboratory, is supported by the US Department of Energy, Office of Science, Office of Basic Energy Sciences under Contract No. DEAC02-76SF00515.

\section{Author contributions}

P.Z. designed the experiments, fabricated and measured the devices, carried out the TEM characterization, carried out and analyzed the XPS measurements, and wrote the paper. L.L. and D.N. carried out XAS characterization, analyzed the data and helped to revise the paper. H.C. and L.F. carried out SEM characterization, analyzed the data, and helped to revise the paper. B.Z., X.S., and Q.D. contributed to the revision and discussion of the paper. L.S. supervised the project and wrote the paper.

\section{Additional information}

Supplementary Information accompanies this paper at https://doi.org/10.1038/s41467017-02429-9.

Competing interests: The authors declare no competing financial interests.

Reprints and permission information is available online at http://npg.nature.com/ reprintsandpermissions/

Publisher's note: Springer Nature remains neutral with regard to jurisdictional claims in published maps and institutional affiliations.

\begin{abstract}
(c) (i)
Open Access This article is licensed under a Creative Commons Attribution 4.0 International License, which permits use, sharing, adaptation, distribution and reproduction in any medium or format, as long as you give appropriate credit to the original author(s) and the source, provide a link to the Creative Commons license, and indicate if changes were made. The images or other third party material in this article are included in the article's Creative Commons license, unless indicated otherwise in a credit line to the material. If material is not included in the article's Creative Commons license and your intended use is not permitted by statutory regulation or exceeds the permitted use, you will need to obtain permission directly from the copyright holder. To view a copy of this license, visit http://creativecommons.org/ licenses/by/4.0/
\end{abstract}

(c) The Author(s) 2018 